\title{
INFLUENCE OF CLIMATE CHANGES ON WATER RESOURCES IN MOLDOVA
}

\author{
Violeta Ivanov \\ Committee on Environment and Climate Changes, Moldovan Parliament, Bd. Stefan cel Mare 162, Chisinau, MD-2073 \\ Phone.(373 22) 235754 /268 346,Fax:(373 22)268346,E-mail:violeta.ivanov@gmail.com
}

\begin{abstract}
The paper aims to analyze the current state of affairs with water resources in Moldova, the challenges it faces for its national human and economic development, having in mind that the water resources are quite limited in Moldova, which encounters pollution, degradation influenced by climate change and unwise human activity to their biodiversity and ecosystems, availability and accessibility. It also attempts to highlight the relationship between climate change and water resources in Moldova, which has adverse effects on both environment and people's health, and raise significant hurdles to the international, regional and sectoral development.
\end{abstract}

Keywords: climate change, water resources, freshwater, pollution, degradation.

Water pollution is among the most critical environmental challenges worldwide having extremely serious consequences for both environment and people's health. One of such consequences is the degradation of water resources influenced by climate changes. The relationship between climate change and water resources are interconnected in complex ways.

One may say that climate change is only one of many factors influencing the future supply and demand for water. Indeed, population, technology, economic conditions, social and political factors, and the values society places on alternative water uses are likely to have more of an impact on the future availability and use of water than changes in the climate. Nevertheless, scientists around the world now agree that the climatic changes occurring internationally are the result of human activity, and the climate change, be it through heightened water insecurity, increased exposure to extreme weather events, environmental degradation or loss of natural resources, biodiversity and ecosystems, may raise significant hurdles to the international, regional and sectoral development.

Rising global temperatures as a consequence of environment pollution will lead to an intensification of the hydrological cycle, resulting in dryer dry seasons and wetter rainy seasons, and subsequently heightened risks of more extreme and frequent floods and droughts. Changing climate will also have significant impacts on the availability of water, as well as the quality and quantity of water that is available and accessible. The predicted changes in quantity, quality and accessibility to water resources will have important consequences for human populations, through impacts to agriculture and food security, health, economic activity, and conflict over water resources.

As concerns Europe, according to recent researches, climate change is posing two major water management challenges: increasing water stress mainly in southeastern Europe, and increasing risk of floods throughout most of the continent $[1$, p.95].

The climate change effects are already visible in Moldova. On the whole, Moldova is located in an area with quite limited water resources, which results in a high frequency of droughts. For example, from 1990 to 2010 the country has undergone nine droughts, and the most serious one in 2007, and two major floods in 2008 and 2010. The increase in natural disasters, primarily floods and droughts, will further exacerbate issues over water availability and water quality having major impacts on water resources.

And it is proved by the unequal distribution of available water resources and natural moistening. The northern part of Moldova (and the central part to some extent) is currently more or less secured from this point of view, while the southern part suffers from a natural water deficit. At the same time, medium and long distance water transfer systems are almost non-existent in the south [3. p.57]. This region is among the most exposed to water shortages. Moreover, local surface water resources in the south (and, less frequently, in the central part of the country) are exposed already today to depletion in drought years (like in 2007). However the water scarcity area, has, as it extends northwards, already reached the most populated areas, which place the biggest load on water resources and are most intensive in water use.

Under the 2010 OECD Report on Moldova the country's economy is very vulnerable to environmental factors, mainly because of its reliance on agricultural production [4]. Demand for agricultural and domestic water in particular increases significantly at hotter and drier times of the year. Agriculture has always been the dominant end-use of diverted water; this only intensifies with increasing needs for irrigation brought on by higher temperatures and reduced precipitation.

Besides the growing needs for irrigation there is another threat to freshwater resources and in particular ecological degradation. Ecosystems can be severely changed or destroyed by water pollution. Many areas are now being affected by careless human pollution, and this pollution is coming back to hurt humans. 
The main source of freshwater pollution can be attributed to discharge of untreated waste, dumping of industrial effluent, and run-off from agricultural fields. Urbanization and the increasing use of synthetic organic substances have serious and adverse impacts on freshwater bodies. The protection of water resources and their quality is closely interrelated with health and reducing water-related diseases. It is a well-known fact that clean water is absolutely essential for healthy living. Adequate supply of fresh and clean drinking water is a basic need for all human beings.

As far as we know, in fact all types of water pollution are harmful to the health of humans. Water pollution may not damage our health immediately but can be harmful after long term exposure. The effects of water pollution are varied and depend on what chemicals are dumped and in what locations.

And the situation in Bubuieci village may serve as a strong example in Moldova of how badly pollution can damage water and people's health. Throughout recent years the waste mud from the Chisinau Water Treatment Plant and other domestic untreated waste is stocked on Bubuieci village outskirts. This has led to ground water pollution through runoff and hazardous substances trickling onto the soil, air, and wells. The negative human health effects are already evident. And in particular, during the last 4 years the number of serious diseases, such as cancer, increased by $30 \%$. The physicians claim the growing number of respiratory diseases in children, tuberculosis, thyroid function abnormality, etc. because of use of ground waters, which proved to be seriously polluted with nitrates and nitrites, exceeding the maximum acceptable concentration (MAC) by hundreds of times, as well as the maximum permissible concentration of heavy metals such as lead, mercury, zinc, etc.

Furthermore, Moldova's water resources are made up of surface ( 70 percent) and underground waters ( 30 percent), including ground waters. Throughout the past twenty years, economic circumstances have had a much stronger influence on water supply dynamics than natural factors. However, both types of water resources in the Republic of Moldova, in particular surface waters, are vulnerable and sensitive to climate change with regard to their quantity and quality. Water quality is also threatened by degradation due to natural, non-pollution, factors. Thus, an increase in air temperature and excessive water pollution will lead to an increase of the temperature of the surface waters and diminishing dissolved oxygen (DO) level, which may result in degradation of surface waters in Moldova.

The surface water resources are the main source of water supply in Moldova, and the largest artery is the Dniester River (which is proved by the fact that 93 percent of water supply for the capital city of Moldova, Chisinau municipality, comes from the Dniester River), and its waters are degrading under influence of climate changes and technogenic disasters. The significant anthropogenic impact on the ecosystem of the Dniester River has the hydropower installations, built in Ukraine, which already lead to irreversible processes and degradation of the River as a whole, and extinction of a number of fish species.

Nowadays a number of power plants are functioning on the Dniester, in particular, the Dnestrovsk Power Plant (GES-1), the Hydropower complex (GES-2) in Naslavcea village, the Dubossar Hydroelectric Power Plant, the water reservoir of which, according to the recent researches by both Moldovan and Ukrainian scholars, is heavily silted and virtually all its bottom is covered with a layer of aquatic vegetation; and the Novodnestrovsk Power Plant.

Under the influence of exploitation of the Dnestrovsk Power Plants aimed only to satisfy the energy needs without appropriate environmentally sound downstream water releases the Dniester River turns into a lake-type reservoir with all the consequences. The physical and chemical properties of river water have been changing as well and in particular thermal, gas, water transparency regimes, composition of suspended substances. Unnatural water-level and temperature fluctuations in the river have had a negative impact on the fish reproduction, valuable fish species have virtually disappeared.

The Novodnestrovsk Power Plant functioning would possibly lead to catastrophic changes in the Dniester River ecosystem. Suffice it to note that besides the changes in the hydrological regime of the River, in the process of water injection and release through pipelines more than $80 \%$ of plankton organisms die. The negative effects for the river basin would also have the channel "align", which will inevitably lead to an imbalance between ground and surface waters. The Dniester River water level has already decreased by 1 meter. And the lack of water in the Dniester delta may lead to the destruction of the biodiversity of the region, because rare for Ukraine and the world otter, European mink, ermine, yellow heron, white-tailed eagle, black stork are breeding there. Therefore, the natural balance of the Dniester River is important for both Ukraine and Moldova, and its delta is protected under the Ramsar Convention (Convention on Wetlands of International Importance).

All the above have led to serious degradation of the Dniester River water quality, extinction or considerable decline of certain species of fish, animals and birds, and the river plants are also changing into species more characteristic to stagnant and boggy waters.

Unfortunately, it should be mentioned that Ukraine have been failing to submit so far the Environment Impact Assessment of the Novodnestrovsk Power Plant functioning, which it was bound to submit long before under Article 6 of the Espoo Convention (Convention on Environmental Impact Assessment in a Transboundary Context).

As concerns the underground waters quality in Moldova, their pollution is often caused by ammonium, sulphuretted hydrogen, and other chemical compounds. According to the data provided by the sanitary-epidemiological service, more than $60 \%$ of Moldova's population consumes water with inadequate concentrations of pollutants, because the quality of 
groundwater in most cases fails to meet the requirements for domestic drinking water. Inspections of wells and springs proved that more than $71 \%$ of wells and $50 \%$ of springs are not safe for use in the household drinking water. And, the nitrate contamination found in $48 \%$ of wells and $35 \%$ of springs pose the greatest danger. Fluorine in unacceptable concentrations is found in $8.5 \%$ of springs and $90 \%$ of wells.

In recent times the pollution of groundwater with pesticides and other nutrients is increasingly serious challenge for Moldova. Pesticides are carried in rainwater runoff from farm fields, suburban lawns, or roadside embankments into the nearest creeks and streams.

Another challenge for water resources is posing deforestation, which in turn has its contribution to climate change, resulting in a drier climate. It is generally known that the lesser is the forest surface, the lesser water the region has. On the other hand, the lack of trees may also contribute to flooding should the erosion occurs due to increased runoff (unabsorbed rainfall). The Republic of Moldova is sparsely wooded and deficient in forest resources, and the forests are unequally distributed as well, the lesser degree of forestation is observed in the southern part. According to FAO [2], the area of forest (386 $000 \mathrm{ha}$ ) accounts for about 11 percent of the land area, which is considerably less than in other European countries. Given the raggedness of the terrain, the low proportion of forest area, the high level of soil erosion, the aridity of the climate and the high population density, forests in Moldova are very important, both ecologically and socially, having in mind that land degradation is a major problem throughout the country. According to specialists, the negative influence of climate factors and the low biological resistance of the forests encourage periodic outbreaks of infestation and disease.

In conclusion, it may be said that the situation with the water resources in Moldova is alarming. Notwithstanding that the water resources and freshwater supply is of primary concern for Moldova and for its national human and economic development, freshwater-related issues need higher attention from both politicians and scholars, with active involvement of civil society, to help mitigate adverse effects of climate changes on water resources, improve the current water management practices, minimize and stop water pollution and deforestation, to jointly seek ways to address the above challenges. There is also a strong need in improved legislation, which would help water protection, conservation, its effective management, green economy implementation and environmental education.

\section{References}

[1]. Bates, B.C.; Kundzewicz Z.W.; Wu S; Palutikof J.P., Eds., 2008: Climate Change and Water. Technical Paper of the Intergovernmental Panel on Climate Change, IPCC Secretariat, Geneva, pp 210.

[2]. Global Forest Resources Assessment 2010, Country Report, Republic of Moldova; Food and Agriculture Organization of the United Nations, Forestry Department FRA2010/134 Rome, 2010; http://www.fao.org/docrep/013/ al569E/al569e.pdf

[3]. NHDR 2009/2010 Climate Change in Moldova. Socio-Economic Impact and Policy Options for Adaptation; UNDP in Moldova, 2009; pp 244.

[4]. OECD Report on Capacity Development for Environmental Management in Moldova: Drivers, links to planning and methods of assessment; EAP Task Force 2010; http://www.oecd.org/dataoecd/30/44/45559222.pdf 